\title{
Association Between Sleep Characteristics and Asthma Control in Middle-Aged and Older Adults: A Prospective Cohort Study
}

This article was published in the following Dove Press journal: Journal of Asthma and Allergy

\section{Suguru Sato (1) \\ Junpei Saito \\ Atsuro Fukuhara \\ Manabu Uematsu \\ Yasuhito Suzuki \\ Mami Rikimaru \\ Takaya Kawamata \\ Takashi Umeda \\ Tatsuhiko Koizumi \\ Ryuichi Togawa \\ Yuki Sato \\ Takefumi Nikaido \\ Hiroyuki Minemura \\ Kenya Kanazawa \\ Yoshinori Tanino \\ Yoko Shibata (D)}

Department of Pulmonary Medicine, School of Medicine, Fukushima Medical University, Fukushima, 960-1295, Japan
Correspondence: Suguru Sato

Department of Pulmonary Medicine, School of Medicine, Fukushima Medical

University, Hikarigaoka-I, Fukushima,

960-1295, Japan

Tel $+8 I-24-547-1360$

Fax +8I-24-548-9366

Email suguru@fmu.ac.jp
Background: Nocturnal asthma symptoms are a well-known feature of sleep disturbance. However, there are few reports on the association between sleep-related characteristics and asthma exacerbation. The aim of the current prospective observational study was to explore the factors while sleeping associated with future asthma exacerbation.

Materials and Methods: At baseline, adult asthmatics underwent home sleep monitoring by a Watch-PAT instrument and then they were prospectively followed-up for the occurrence of exacerbations. The number of asthma exacerbation was observed over a period of one year, and multivariable analyses of the factors associated with asthma exacerbation were performed.

Results: A total of 62 asthmatic subjects were enrolled (mean age 62.1 years), 59 of whom were finally included in the prospective observational study. Obstructive sleep apnea (defined by an apnea-hypopnea index based on peripheral arterial tone more than 5 times/hour) were observed in $81 \%$ of the subjects. During the one-year monitoring period, 14 of the 59 subjects $(24 \%)$ used occasional systemic corticosteroids for their exacerbation asthma (worsened group) while the other 45 subjects did not experience asthma exacerbation (stable group). A comparison of the baseline clinical characteristics and sleep-related data between the two groups, mean forced expiratory volume one second percent $\left(\mathrm{FEV}_{1} / \mathrm{FVC}\right)$, mean baseline Asthma Control Test (ACT) score, median pAHI value, and median oxygen desaturation index value were significantly lower in the worsened group than those in the stable group. Additionally, mean prevalence of the left lateral decubitus (LLD) position in sleep monitoring were significantly higher in the worsened group than that in the stable group. Among the independent variables, baseline asthma severity, ACT score, and the LLD position showed significant associations with asthma exacerbation.

Discussion/Conclusion: The present study identified that sleeping in the LLD position was also associated with asthma exacerbation.

Keywords: asthma, asthma control, sleep position, asthma exacerbation

\section{Background}

Asthma is a chronic inflammatory airway condition that is characterized by symptoms that worsen overnight, particularly in the early hours of the morning. Sleep disturbance due to nocturnal symptoms typically represents poor asthma control. Asthma is associated with decreased subjective quality of sleep and increased daytime sleepiness. ${ }^{1,2}$ Asthmatic subjects often report feeling sleepy and tired during the day. ${ }^{3-6}$ A major cause of sleep disturbance in asthmatic subjects is an 
increase in bronchial hyper-responsiveness and airway resistance overnight, which potentially exacerbates nocturnal asthma symptoms. ${ }^{7,8}$ It was also suggested that gastroesophageal reflux events are related to sleep disturbance in asthmatic subjects. ${ }^{9}$ Moreover, a circadian variation in airway inflammation was reported by a study of bronchoalveolar lavage fluid in asthmatic subjects ${ }^{10}$ and this was supported by another study that focused on fractional exhaled nitric oxide (FeNO) levels. ${ }^{11}$

In addition, many studies have shown that asthmatics have increased symptoms of sleep-disordered breathing, and have demonstrated an increased prevalence of obstructive sleep apnea (OSA) compared with controls without asthma. ${ }^{12}$ In particular, OSA was reported to be more prevalent among severe asthmatics compared with moderate asthmatics and control subjects. ${ }^{13,14}$ One prospective study demonstrated that asthmatic subjects without OSA had a higher incidence of OSA over an eight-year period than controls. ${ }^{15}$ Furthermore, the results of previous studies on asthmatic subjects with OSA using continuous positive airway pressure (CPAP) suggested that treating OSA may lead to improved quality of life in such subjects. ${ }^{16-18}$ However, previous studies on the effect of OSA risk on asthma-related clinical outcomes have reported conflicting results. ${ }^{13,19}$ The pathophysiological mechanisms involved in the direct interaction between asthma and OSA have not yet been fully elucidated. Moreover, the effects of confounders, such as obesity and age, were not adequately excluded in the previous studies.

To our knowledge, there are few reports on the association between sleep-related characteristics and disease control in asthmatic subjects. There are also few prospective studies that explore OSA and asthma exacerbation. The aim of the present study was to explore the factors in sleep-related characteristics associated with future asthma exacerbation. Here, we conducted night-time sleep monitoring of asthmatic subjects by using a 4-channel unattended home device and performed a prospective one-year observational study about asthma exacerbation.

\section{Methods}

\section{Study Subjects and Design}

This is a prospective observational study which was conducted in the Department of Pulmonary Medicine in Fukushima Medical University from October 2016 to June 2018. Study participants were adult subjects with asthma who regularly visited outpatient clinics at the Department of Pulmonary Medicine in Fukushima Medical University Hospital. We enrolled asthmatic subjects who were receiving standard asthmatic treatment by their attending physician and had to be free of asthma attacks for at least four weeks before starting investigation. Asthmatic subjects who were diagnosed as having OSA, upper or lower airway infection, malignancy, collagen vascular disease, cerebrovascular disease, and heart disease at the study entry and who were treated for OSA were excluded from the study. All subjects provided written informed consent for analysis of their clinical data, and the study was approved by the Ethics Committee of Fukushima Medical University (IRB number 2845). This study was conducted in accordance with the Declaration of Helsinki.

Asthma was defined on a basis of recurrent episodes of at least one symptom (cough, wheeze, or dyspnea) associated with a demonstrated reversible airflow limitation (12\% and $200 \mathrm{~mL}$ variability in forced expiratory volume in one second $\left[\mathrm{FEV}_{1}\right]$, either spontaneously or with an inhaled short-acting $\beta_{2}$-agonist) and/or increased airway responsiveness, and all study subjects were diagnosed according to the American Thoracic Society (ATS) criteria. ${ }^{20}$ Asthma control status and severity were assessed according to the modified definitions of the Asthma Prevention and Management Guideline 2015, Japan (JGL 2015). ${ }^{21}$ Atopy was defined as either a nonspecific IgE concentration greater than or equal to $250 \mathrm{IU} /$ $\mathrm{mL}$ or any positive antigen-specific IgE (greater than or equal to $0.70 \mathrm{UA} / \mathrm{mL}$ ), as described previously. ${ }^{22}$

First, study participants were recruited between October 2016 and June 2017. They underwent a pulmonary function test, FeNO measurement, and Asthma Control Test (ACT) as baseline data for evaluating their asthma control status. Clinical characteristics (age, gender, height, body weight, duration of asthma treatment, atopic status and comorbidities) and treatment-related information (asthma severity, treatment contents and history of asthma deterioration) were obtained. The subjects themselves performed night-time home sleep monitoring for one night and completed a self-evaluation with two questionnaires related to sleep quality. We obtained sleeprelated data (apnea-hypopnea index [AHI] based on peripheral arterial tone [PAT], total sleeping time, sleep latency, rapid eye movement [REM] sleep latency, composition of sleep stages, wake/sleep balance, nocturnal awaking time, prevalence of sleep posture, heart rate, arterial 
oxygen saturation and sleeping position) from the home sleep monitoring. All study subjects who having OSA based on the results of the home sleep monitoring were recommended to undergo a polysomnography test by their attending physician. As a result, subjects who began any treatment for OSA (CPAP therapy or oral appliance) were excluded from the study.

Second, we prospectively investigated the number of asthma exacerbations for one year from the date when home sleep monitoring was performed. The study subjects were followed-up by their attending physician regularly. During the observational period, asthma treatment remained unchanged from baseline evaluation. Rescue use of short-acting $\beta_{2}$ agonist was permitted as symptom relief. In the current study, asthma exacerbation was defined as the onset or worsening of asthmatic symptoms (cough, sputum production, wheezing and dyspnea) that require occasional use of systemic corticosteroids. The study subjects contacted their attending physician for evaluation in cases where the onset or worsening of their respiratory symptoms occurred. If systemic corticosteroids could be administered to study subjects as rescue medication, the amount of corticosteroids used and the time of administration were recorded.

\section{Sleep Assessment}

All asthmatics enrolled in this study underwent night-time monitoring of their sleep using Watch-PAT 200 (Itamar Medical, Caesarea, Israel), which is a 4-channel (PAT signal, heart rate, pulse oximetry, and actigraphy) unattended home device, categorized as a Level 3 device by the American Academy of Sleep Medicine. The system used in this study is based on a wrist-worn device and a finger probe which acquires PAT signals and arterial oxygen saturation levels, together with actigraphy data from a 3D accelerometer that is embedded in the wrist unit, and an optional snoring and body position sensor that is positioned under the sternal notch. PAT signals measure arterial pulsatile volume changes of the finger that are regulated by alpha-adrenergic innervation of the smooth muscles of the vasculature of the finger, reflecting nervous system activity. This augmentation in sympathetic activity accompanies an increase in heart rate and desaturation at the termination of respiratory events. The Watch-PAT algorithm detects offline apnea-hypopnea events, respiratory effort-related arousals, and sleep/wake status, and also determines sleep stages. Past studies have validated the performance of PAT in detecting sleep disordered breathing. ${ }^{23-25}$ The 4-channel unattended home device used in the present study was validated with polysomnography as a sleep monitoring device. ${ }^{26}$ PAT-AHI (pAHI) is a frequency of respiratory events per hour in actinographydetermined sleep and is calculated using greater than or equal to $3 \%$ of oxygen desaturation. In the present study, OSA was defined as more than five respiratory events per hour (events/hour) according to pAHI. Moreover, pAHI of more than five but fewer than 15 events/hour, 15 or more but fewer than 30 events/hour, and 30 events/ hour or more were defined as mild OSA, moderate OSA, and severe OSA, respectively.

\section{Asthma Control Assessment}

Pulmonary function testing was performed using rolling seal spirometers (Chestac-11 Cyber S-type; Chest MI, Inc., Tokyo, Japan) to measure forced vital capacity (FVC) and $\mathrm{FEV}_{1}$ by experienced respiratory technicians according to ATS guidelines. ${ }^{27}$ FVC and FEV $_{1}$ were expressed as percent-predicted values. FeNO measurement was taken according to the ATS and European Respiratory Society recommendations ${ }^{28}$ using a chemiluminescence analyzer (NA623N; Kimoto, Osaka, Japan). Measurement was described previously. ${ }^{22}$ ACT was used for baseline subjective assessment. ${ }^{29}$ In general, an ACT score of more than 19 points indicates well-controlled asthma.

\section{Outcome}

The primary objective of this study was to explore the factors in sleep-related characteristics associated with future asthma exacerbation. To this end, the sleep-related monitoring data were compared between asthmatic subjects with exacerbations and those without exacerbations over the same period. Moreover, multivariate analyses of the factors associated with asthma exacerbation were performed. Asthmatic subjects who began CPAP treatment after home sleep monitoring were excluded.

\section{Statistical Analyses}

All values are expressed as mean \pm standard deviation (SD) or median [interquartile range (IQR)] unless otherwise specified. A comparison of baseline clinical characteristics and sleep-related data between the asthmatic subjects with and without exacerbation over the one-year monitoring study period was performed using MannWhitney $U$-test. Multiple logistic regression analysis was performed to assess factors associated with exacerbation of asthma using a forward selection method. Values of $p<$ 
0.05 were considered statistically significant. Statistical analysis was performed with PASW Statistics Base for Windows (version 25; IBM, Armonk, NY).

\section{Results}

A total of 62 asthmatic subjects (27 males and 35 females) undertook the home sleep monitoring for one year. The characteristics and the results of asthma-related parameters of the 62 subjects are shown in Table 1. The mean (SD) age was 62 (14) years. Severity of asthma was mild intermittent $(n=7)$, mild persistent $(n=13)$, moderate persistent $(n=25)$, and severe persistent $(\mathrm{n}=17)$. A total of $48(77 \%)$ subjects had atopy, and the mean (SD) duration of asthmatic treatment was 13 (11) years. The mean (SD) ACT score was 20.9 (4.4) points, and the number of subjects with well-controlled asthma ( $>19$ points) was $42(68 \%)$. Over a year before the sleep monitoring, a total of 15 (24\%) individuals occasionally used systemic corticosteroids for asthma exacerbation.

In home sleep monitoring, there were no malfunctions in the device and no lack of study data. The sleep monitoring data of the 62 subjects are shown in Table 2. Regarding sleep monitoring, the median [IQR] pAHI was 10.4 [5.2-21.5] events/hour and the number (\%) of subjects with pAHI of more than five events/hour was $50(81 \%)$. From the sleep monitoring results, a total of 26 individuals had mild OSA, 17 had moderate OSA, and seven had severe OSA. There were no significant correlations observed between pAHI and the characteristics of the asthmatic subjects in Table 1, except for body mass index (BMI) $(r=0.547, p<0.001)$.

\section{Sleep-Related Variables Associated with Asthma Exacerbations}

All study subjects were informed of their own results of the sleep monitoring. Three subjects were excluded from the prospective assessment because they had begun a CPAP therapy for their high pAHI levels in sleep monitoring. The remaining subjects did not wish to undergo treatment for OSA. During the one-year monitoring period, 14 of the 59 subjects (24\%) used occasional systemic corticosteroids for their exacerbation asthma (worsened group) while the other 45 subjects did not experience asthma exacerbation (stable group). In the worsened group, mean (SD) days of occasional systemic corticosteroids administration was 16.0 (15.3) days and mean (SD) dose of systemic corticosteroids equivalent to prednisolone was 21.2 (4.4) $\mathrm{mg}$ per day. Eight of 14 subjects (57\%) had asthma worsening requiring occasional use of systemic
Table I Characteristics and Control-Related Parameters of Asthmatic Subjects

\begin{tabular}{|c|c|}
\hline Characteristics & Finding \\
\hline Number of subjects & 62 \\
\hline Age, mean (SD), year & $62.1(14.2)$ \\
\hline Gender, male/female, N (\%) & $27(44) / 35(56)$ \\
\hline BMI, mean (SD) & $24.8(5.2)$ \\
\hline $\begin{array}{l}\text { Duration of asthma treatment, mean } \\
\text { (SD), year }\end{array}$ & $13(1 \mathrm{I})$ \\
\hline Atopy/non-atopy, N (\%) & $48(77) / 14(23)$ \\
\hline $\begin{array}{l}\text { Severity of asthma: mild intermittent/mild } \\
\text { persistent/moderate persistent/severe } \\
\text { persistent, } N(\%)\end{array}$ & $\begin{array}{c}7(1 \mathrm{I}) / 13(2 \mathrm{I}) / 25 \\
(40) / 17(28)\end{array}$ \\
\hline $\begin{array}{l}\text { Control status of asthma: well-controlled/ } \\
\text { insufficiently-controlled/poorly-controlled, } \\
\mathrm{N}(\%)\end{array}$ & $\begin{array}{c}21(34) / 26(42) / 15 \\
(24)\end{array}$ \\
\hline Allergic rhinitis, $N(\%)$ & $27(44)$ \\
\hline Chronic sinusitis, N (\%) & $21(34)$ \\
\hline $\begin{array}{l}\text { Dose of ICS (equivalent to fluticasone } \\
\text { propionate): mean (SD), } \mu g / \text { day }\end{array}$ & $534(342)$ \\
\hline Use of LABA, N (\%) & $48(77)$ \\
\hline Use of LTRA, N (\%) & $38(61)$ \\
\hline Use of theophylline, $\mathrm{N}$ (\%) & $18(29)$ \\
\hline Use of LAMA, N (\%) & $10(16)$ \\
\hline Use of omalizumab, $\mathrm{N}(\%)$ & $3(5)$ \\
\hline Maintenance oral corticosteroids, N (\%) & $5(8)$ \\
\hline $\begin{array}{l}\text { Dose of oral corticosteroids (equivalent to } \\
\text { prednisolone), mean (SD), mg/day }\end{array}$ & $3.8(1.6)$ \\
\hline$\%$ predicted FVC, mean (SD), \% & $102.6(16.3)$ \\
\hline$\%$ predicted $\mathrm{FEV}_{\mathrm{l}}$, mean $(\mathrm{SD}), \%$ & $88.3(23.4)$ \\
\hline $\mathrm{FEV}_{\mathrm{I}} / \mathrm{FVC}$, mean (SD), \% & $71.3(13.8)$ \\
\hline FeNO, median [IQR], ppb & $34.6[23.7-65.6]$ \\
\hline ACT global score, mean (SD), points & $20.9(4.4)$ \\
\hline ACT score $>19$ points, $N(\%)$ & $42(68)$ \\
\hline $\begin{array}{l}\text { Subjects with occasional use of systemic } \\
\text { corticosteroids over one year before the } \\
\text { monitoring, } \mathrm{N}(\%)\end{array}$ & $15(24)$ \\
\hline
\end{tabular}

Abbreviations: BMI, body mass index (calculated as weight in kilograms divided by square of height in meters); ICS, inhaled corticosteroids; LABA, long-acting $\beta 2$-agonist; LTRA, leukotriene receptor antagonist; LAMA, long-acting muscarinic antagonist; $F V C$, forced vital capacity; $\mathrm{FEV}_{\mathrm{l}}$, forced expiratory volume in one second; FeNO, fractional exhaled nitric oxide; ppb, parts per billion; ACT, Asthma Control Test. 
Table 2 Summary of Sleep Monitoring Data and the SleepRelated Questionnaire Scores

\begin{tabular}{|c|c|c|c|}
\hline & & & Finding \\
\hline \multirow{18}{*}{$\begin{array}{l}\text { Watch PAT data } \\
(n=62)\end{array}$} & \multicolumn{2}{|c|}{ Sleep duration, hour } & $6.4(1.3)$ \\
\hline & \multicolumn{2}{|c|}{ Nocturnal awaking, times } & $6.6(4.9)$ \\
\hline & \multicolumn{2}{|c|}{ Sleep latent time, minutes } & $20.7(10.9)$ \\
\hline & \multicolumn{2}{|c|}{ REM latent time, minutes } & $95.3(66.6)$ \\
\hline & \multicolumn{2}{|c|}{ Balance of wake/sleep, \% } & I7.0 (9.7)/ \\
\hline & \multirow{4}{*}{$\begin{array}{l}\text { Sleep } \\
\text { stage }\end{array}$} & & \\
\hline & & REM sleep, \% & $25.8(7.7)$ \\
\hline & & $\begin{array}{l}\text { Light sleep (Stage I } \\
\text { or } 2 \text { ), } \%\end{array}$ & $56.6(12.7)$ \\
\hline & & $\begin{array}{l}\text { Deep sleep (Stage } 3 \\
\text { or } 4 \text { ), } \%\end{array}$ & I8.3 (7.6) \\
\hline & \multicolumn{2}{|c|}{ Mean pulse rate,/minutes } & $66.2(9.8)$ \\
\hline & \multicolumn{2}{|c|}{ Mean oxygen saturation, \% } & $94.5(1.9)$ \\
\hline & \multicolumn{2}{|c|}{ pAHI, events/hour } & $\begin{array}{c}10.4 \\
{[5.2-21.5]}\end{array}$ \\
\hline & \multicolumn{2}{|c|}{$\mathrm{pAHI}>5$, number (\%) } & $50(8 \mathrm{I})$ \\
\hline & \multicolumn{2}{|c|}{ ODI, events/hour } & $\begin{array}{c}4.6 \\
{[1.9-13.8]}\end{array}$ \\
\hline & \multirow{4}{*}{$\begin{array}{l}\text { Body } \\
\text { position }\end{array}$} & Supine, $\%$ & $45.8(27.5)$ \\
\hline & & Prone, \% & $4.8(8.4)$ \\
\hline & & RLD, \% & $23.7(22.2)$ \\
\hline & & LLD, \% & $25.5(19.7)$ \\
\hline
\end{tabular}

Note: Data are presented as mean (SD) or median [IQR] of subjects unless otherwise indicated.

Abbreviations: REM, rapid eye movement; $\mathrm{PAHI}$, peripheral arterial tone apnea hypopnea index; ODI, oxygen desaturation index; RLD, right lateral decubitus; LLD, left lateral decubitus.

corticosteroids in the consecutive two years. A comparison of the baseline clinical characteristics and sleep-related data between the two groups is shown in Table 3. Mean (SD) forced expiratory volume one second percent $\left(\mathrm{FEV}_{1} /\right.$ FVC), mean ACT score, median pAHI and median ODI value were significantly lower in the worsened group than those in the stable group ( $p=0.036, p<0.001, p=0.020$, and $p=0.019$, respectively). Additionally, prevalence of the left lateral decubitus (LLD) position in sleep monitoring were significantly higher in the worsened group than that in the stable group (39.3 [18.5] \% and 22.5 [18.3] \%, respectively; $p=0.004)$. Moreover, the mean (SD) duration of sleep in the LLD position was significantly longer
Table 3 Comparison of Baseline Clinical and Sleep Monitoring Characteristics of Asthmatics with and without Exacerbation in One Year

\begin{tabular}{|c|c|c|c|c|}
\hline & & $\begin{array}{l}\text { Worsened } \\
\text { Group }\end{array}$ & $\begin{array}{l}\text { Stable } \\
\text { Group }\end{array}$ & $p$ value \\
\hline \multicolumn{2}{|c|}{ Number of subjects } & 14 & 45 & - \\
\hline \multicolumn{2}{|l|}{ Age, year } & $62(15)$ & $62(15)$ & 0.936 \\
\hline \multicolumn{2}{|c|}{ Gender, male/female } & $6 / 8$ & $19 / 26$ & 0.967 \\
\hline \multicolumn{2}{|l|}{ BMI, $\mathrm{kg} / \mathrm{m}^{2}$} & $23.7(4.6)$ & $24.4(4.5)$ & 0.510 \\
\hline \multicolumn{2}{|c|}{$\%$ predicted $\mathrm{FEV}_{1}, \%$} & $77.6(31.1)$ & $94.7(16.7)$ & 0.050 \\
\hline \multicolumn{2}{|c|}{$\mathrm{FEV}_{1} / \mathrm{FVC}, \%$} & $61.6(17.8)$ & 73.7 (II.3) & $0.036^{*}$ \\
\hline \multicolumn{2}{|l|}{ FeNO, ppb } & $\begin{array}{c}51.3 \\
{[24.5-159.8]}\end{array}$ & $\begin{array}{c}34.2 \\
{[21.3-62.7]}\end{array}$ & 0.327 \\
\hline \multicolumn{2}{|c|}{ ACT score, point } & I6.2 (4.6) & $22.2(3.4)$ & $<0.0001 *$ \\
\hline \multicolumn{2}{|c|}{$\begin{array}{l}\text { Asthma Severity: } \\
\text { mild intermittent/mild } \\
\text { persistent/moderate } \\
\text { persistent/severe } \\
\text { persistent }\end{array}$} & $0 / 2 / 4 / 8$ & $6 / 11 / 21 / 7$ & $0.015^{*}$ \\
\hline \multicolumn{2}{|c|}{ Sleep duration, hour } & $6.3(0.9)$ & $6.5(1.5)$ & 0.618 \\
\hline \multicolumn{2}{|c|}{$\begin{array}{l}\text { Nocturnal awakening, } \\
\text { events/night }\end{array}$} & $6.8(3.9)$ & $6.2(5.1)$ & 0.480 \\
\hline \multirow[t]{3}{*}{ Sleep stage } & $\begin{array}{l}\text { REM sleep, } \\
\%\end{array}$ & $24.9(6.2)$ & $26.3(8.2)$ & 0.433 \\
\hline & $\begin{array}{l}\text { Light sleep, } \\
\%\end{array}$ & $57.2(10.6)$ & $55.7(13.0)$ & 0.563 \\
\hline & $\begin{array}{l}\text { Deep } \\
\text { sleep, \% }\end{array}$ & $18.0(5.7)$ & $18.0(7.3)$ & 0.708 \\
\hline \multicolumn{2}{|c|}{$\mathrm{pAHI}$, events/hour } & $5.3[2.6-9.8]$ & $\begin{array}{c}12.1 \\
{[5.8-21.8]}\end{array}$ & $0.020^{*}$ \\
\hline \multicolumn{2}{|c|}{ ODI, events/hour } & $1.9[0.7-4.5]$ & $\begin{array}{c}5.1 \\
{[2.5-\mid 1.8]}\end{array}$ & $0.019 *$ \\
\hline \multicolumn{2}{|c|}{$\begin{array}{l}\text { OSA severity: } \\
\text { normal/mild/moderate/ } \\
\text { severe }\end{array}$} & $6 / 6 / 2 / 0$ & $6 / 20 / 14 / 5$ & 0.064 \\
\hline \multirow{4}{*}{$\begin{array}{l}\text { Body } \\
\text { position }\end{array}$} & Supine, \% & $39.3(26.6)$ & $48.9(27.4)$ & 0.273 \\
\hline & Prone, \% & $5.5(8.4)$ & $4.8(8.7)$ & 0.907 \\
\hline & RLD, \% & $15.0(17.3)$ & $23.7(20.6)$ & 0.112 \\
\hline & LLD, \% & $39.3(18.5)$ & $22.5(18.3)$ & $0.004 *$ \\
\hline
\end{tabular}

Notes: Data are presented as mean (SD) or median [IQR] of subjects unless otherwise indicated. $* p<0.05$.

Abbreviations: $\mathrm{BMI}$, body mass index; $\mathrm{FEV}_{1}$, forced expiratory volume in one second; FeNO, fractional exhaled nitric oxide; ACT, Asthma Control Test; REM, rapid eye movement; PAHI, peripheral arterial tone apnea hypopnea index; ODI, oxygen desaturation index; OSA, obstructive sleep apnea; RLD, right lateral decubitus; LLD, left lateral decubitus. 
than that in the stable group $(2.46$ [1.22] $\mathrm{h}$ and 1.52 [1.38] $\mathrm{h}$, respectively; $p=0.026$ ) (shown in Figure 1). Comparisons of detailed data in the sleep monitoring of asthmatics with and without exacerbation over one year are shown in Table 4. No significant differences were observed in the pulse rate parameters between these two groups. Mean (SD) of maximum $\mathrm{SpO}_{2}$ levels were significantly lower in the worsened group than that in the stable group (98.2 [1.2] \% and 99.0 [0.8] \%, respectively; $p=$ 0.030 ). Median $[I Q R]$ pAHI value in the supine position was significantly lower in the worsened group than that in the stable group (7.1 [2.7 to 12.9] events/hour and 19.8 [7.1 to 29.8] events/hour, respectively; $p=0.011$ ), while no significant differences were observed regarding median [IQR] pAHI values in other positions. The median prevalence of the LLD position in the 59 asthmatic subjects enrolled in the secondary assessment was $26.6 \%$. To investigate the relationship between probability of initial asthma exacerbation and prevalence of the LLD position, the first asthma exacerbations of 29 asthmatic subjects with $27 \%$ or more prevalence of the LLD position (High \%LLD group) and that of the 30 asthmatic subjects with less than $27 \%$ prevalence of the LLD position (Low \%LLD group) were compared. The Kaplan-Meier plot of the time to first exacerbation is shown in Figure 2. The probability of the first asthma exacerbation in the High \%LLD group was significantly higher than that in the Low \%LLD group.

We used multivariate logistic regression modeling to calculate the odds ratios and $95 \%$ confidence intervals after controlling confounders (Table 5). The independent variables that had significant associations with asthma exacerbation

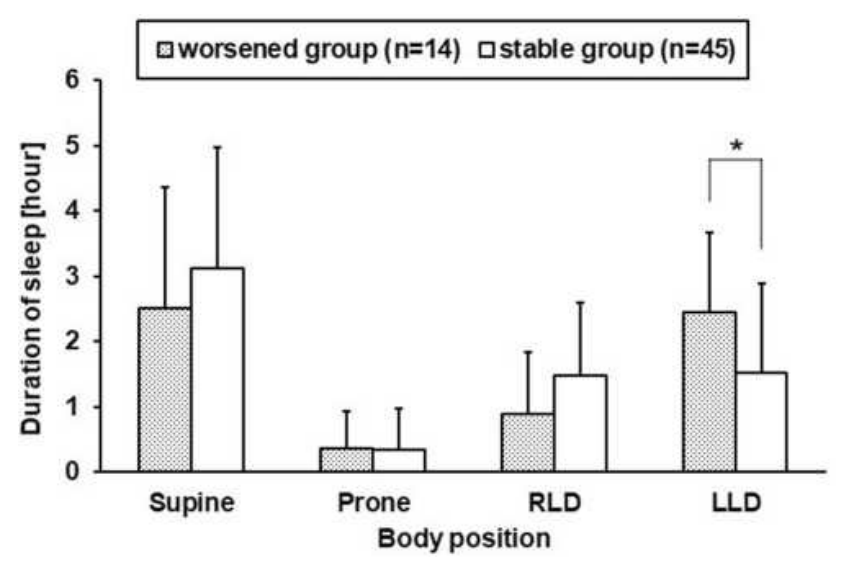

Figure I Comparison of sleep duration in each sleep position. Comparison of the mean (SD) duration of sleep in the supine, prone, right lateral decubitus (RLD) and left lateral decubitus (LLD) positions compared between worsened asthmatic subjects' group $(n=14)$ and stable asthmatic subjects' group $(n=45) . *_{p}<0.05$. requiring occasional use of systemic corticosteroids in the monitoring period were baseline asthma severity, baseline ACT score, and the prevalence of LLD position in sleep monitoring. Among the 59 asthmatic subjects enrolled in the secondary assessment, no significant associations were observed between the prevalence of LLD position in sleep monitoring and asthma-related parameters.

\section{Discussion and Conclusion}

In the prospective study, home sleep monitoring was performed for asthmatic subjects from our outpatient clinic and we investigated the variables associated with asthma exacerbation. We found that the independent variables showing significant associations over an observation period of one year were baseline asthma severity, baseline ACT score, and the LLD position in sleep monitoring.

We explored the sleep-related variables associated with asthma exacerbation. The independent variables that had significant associations with asthma exacerbation requiring occasional systemic corticosteroids in the monitoring period were baseline asthma severity (severe persistent asthma), baseline ACT score and prevalence of the LLD position in sleep monitoring using multivariate logistic regression. No significant difference was observed in baseline FeNO value between the group with and without asthma exacerbations in the one year cohort. FeNO has also been shown to be a predictive factor for asthma exacerbations, with higher levels being associated with a greater number of exacerbations. ${ }^{30}$ In the present study, relatively older asthmatic subjects were enrolled. While FeNO has been extensively studied in adults and children with asthma, there are a limited number of publications about the utility of FeNO in elderly asthmatics. ${ }^{31}$ In our previous study with a similar age group, while both the mean values of the ACT score and \% predicted $\mathrm{FEV}_{1}$ in the asthma control period revealed a significant negative correlation with occasional use of systemic corticosteroids, there was no significant correlation between mean FeNO level in the asthma control period and occasional use of systemic corticosteroids. ${ }^{32}$ More work will have to be done to define the role of exhaled NO in the diagnosis and management of elderly asthmatic patients.

To our knowledge, there have been very few reports on sleeping posture in asthmatic patients. Backon et al reported and strongly recommended that asthmatic patients should avoid sleeping in the right lateral decubitus position because of increasing vagal tone with right sided pressure and a decrease in left sided pressure on the sleeping 
Table 4 Comparison of Detail Data in Sleep Monitoring of Asthmatics with and without Exacerbation in One Year

\begin{tabular}{|c|c|c|c|c|}
\hline & & $\begin{array}{c}\text { Worsened } \\
\text { Group }\end{array}$ & $\begin{array}{l}\text { Stable } \\
\text { Group }\end{array}$ & $p$ value \\
\hline \multicolumn{2}{|c|}{ Number of subjects } & 14 & 45 & - \\
\hline \multirow{3}{*}{$\begin{array}{l}\text { Pulse rate/ } \\
\text { minutes }\end{array}$} & Mean & $67.0(10.1)$ & $64.2(7.8)$ & 0.354 \\
\hline & Minimum & $51.8(7.8)$ & $47.8(6.9)$ & 0.117 \\
\hline & Maximum & $100.7(19.5)$ & $\begin{array}{c}96.7 \\
(11.8)\end{array}$ & 0.487 \\
\hline \multirow[t]{3}{*}{$\mathrm{SpO}_{2}, \%$} & Mean & $94.0(1.8)$ & $94.9(1.6)$ & 0.106 \\
\hline & Minimum & $88.6(4.3)$ & $87.0(5.2)$ & 0.343 \\
\hline & Maximum & $98.2(1.2)$ & $99.0(0.8)$ & $0.030 *$ \\
\hline \multicolumn{2}{|c|}{$\begin{array}{l}\text { Prevalence of time in } \\
\mathrm{SpO}_{2}<90 \%, \%\end{array}$} & I.2(2.9) & I.0 (4.I) & 0.748 \\
\hline \multirow[t]{4}{*}{$\begin{array}{l}\text { PAHI, } \\
\text { events/hour }\end{array}$} & Supine & $\begin{array}{c}7.1[2.7-12.9] \\
(n=13)\end{array}$ & $\begin{array}{c}19.8 \\
{[7.1-29.8]} \\
(n=43)\end{array}$ & $0.011^{*}$ \\
\hline & Prone & $\begin{array}{c}6.5[2.0-14.0] \\
(n=6)\end{array}$ & $\begin{array}{c}4.1 \\
{[0-13.3]} \\
(n=13)\end{array}$ & 0.658 \\
\hline & RLD & $\begin{array}{c}6.5[1.0-15.7] \\
(n=10)\end{array}$ & $\begin{array}{c}6.7 \\
{[2.2-13.2]} \\
(n=37)\end{array}$ & 0.990 \\
\hline & LLD & $\begin{array}{c}3.3[1.8-12.4] \\
(n=13)\end{array}$ & $\begin{array}{c}7.4 \\
{[2.3-16.8]} \\
(n=36)\end{array}$ & 0.239 \\
\hline
\end{tabular}

Note: Data are presented as mean (SD) or median [IQR] of subjects unless otherwise indicated. $*_{p}<0.05$.

Abbreviations: ODI, oxygen desaturation index; RLD, right lateral decubitus; LLD, left lateral decubitus.

positions of asthmatic subjects. ${ }^{33}$ Patients with chronic heart failure tended to avoid the LLD position spontaneously during sleep, and this avoidance was related to the degree of left ventricular filling pressure, cardiac output, and cardiovascular autonomic function. ${ }^{34}$ It has been reported that the left lateral decubitus position is associated with higher sympathetic nerve activity in patients with chronic heart failure. ${ }^{35}$ Sympathetic nerve activity was reported to be associated with bronchodilation in asthmatic airways. A possible reason for sleeping position effect may be a self-protecting mechanism of avoiding airway narrowing by autonomic neural function in uncontrolled asthmatic subjects. In general, a heart rate fluctuation is influenced by vagal tone. In the present study, no significant differences were observed regarding the parameters of pulse rate in whole sleeping time between the worsened group and the stable group. However, to assess the influence of vagal tone by evaluating pulse rate fluctuation, we would have to monitor the patients in each sleeping position separately.

Furthermore, body position affects pulmonary function. The peak expiratory flow (PEF) can be defined as the major flow obtained in an expiratory pressure after a complete inspiration to the level of the total lung capacity in pulmonary function test. PEF depends on the effort and strength of the expiratory muscles, airway diameter and lung volume. ${ }^{36}$ In a study of PEF in healthy young volunteers, the PEF values measured in the sitting position were higher than those in the supine and right lateral decubitus positions, although the differences between the sitting and LLD positions were not significant. ${ }^{37}$ Similarly, in a study of PEF measurements in various positions in healthy obese subjects, there were significant differences among standing position, seated position and LLD position. ${ }^{38}$ Another possible reason also may be a selfprotecting mechanism for preventing decreased effect of the decubitus position on pulmonary function. However, the biological plausibility for the findings regarding sleep position need to be expanded and deepened with greater clinical or physiologic mastery. The prone position is used to improve gas exchange in patients with acute respiratory distress syndrome. ${ }^{39}$ This posture effect is associated with an increase in lung gas content and with a more uniform distribution of aeration, as the increase in aeration in dorsal lung regions was not offset by loss of aeration in ventral regions. ${ }^{40}$ To clarify the posture effect of LLD in asthmatic subjects, we may have to assess the regional distribution of pulmonary shunt, aeration, perfusion, and ventilation in further studies.

The present study has some methodological limitations. First, the mean age of the asthmatic subjects in the present study was relatively high compared to those of previous reports on the association between sleep quality and asthma. ${ }^{41}$ Aging is one of the independent risk factors for OSA. Moreover, it has been suspected that the incidence of OSA in asthmatic subjects rapidly increases with age. ${ }^{15}$ As a result, it is possible that the mean pAHI value and prevalence of asthmatic subjects who had OSA were relatively high compared to those of previous reports. However, one of the aims in our study was to investigate the association between asthma control and OSA. The high prevalence of asthmatic subjects with OSA at baseline may strengthen the reliability of our results. Second, 


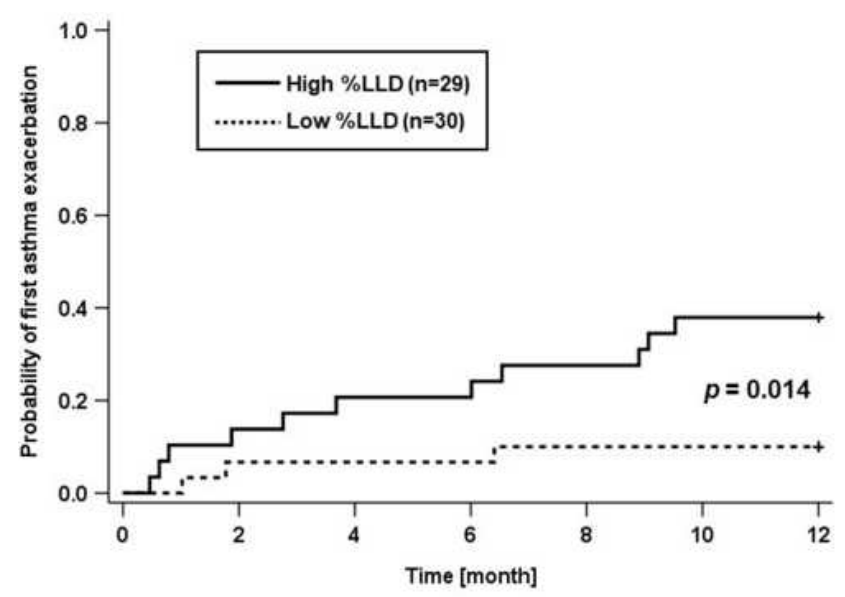

Figure 2 Kaplan-Meier plot of the time to asthma exacerbation. Kaplan-Meier plot of the time to first asthma exacerbation in high and low prevalence of left lateral decubitus (LLD) position (solid line: high prevalence of LLD position group, broken line: low prevalence of LLD position group). A significant higher exacerbation rate was observed in the high LLD prevalence group than that in the low LLD prevalence group, calculated with the Log rank test.

while polysomnography has been used as an objective sleep monitoring tool in several epidemiological studies, home sleep monitoring tool was used in the present study. Third, three asthmatic subjects who had moderate to severe OSA according to their sleep monitoring results were excluded from the secondary assessment because they had begun CPAP therapy. At the secondary assessment, there was a possibility that the study results may require a consideration for applicable to severe OAS subjects with asthma, because of two asthmatic subjects with relatively high pAHI values were excluded from the secondary assessment. However, our study included more than $80 \%$ of asthmatic subjects who had OSA (39\% of asthmatic subjects had moderate to severe OSA). Thus, the reliability of the secondary assessment is considered secured. Fourth, the number of subjects recruited in the present study was approximately $10 \%$ of the asthmatic subjects who visit our outpatient clinic considering the processing capacity of the home sleep monitoring and the entry period of study. They were selected in order of arrival at the clinic. However, in future studies, based on the results of present study we have to consider sample size justification or power analysis.

In conclusion, the present study identified that the LLD sleeping position was associated with future asthma exacerbation. We believe that further studies are warranted to evaluate the mechanisms by which sleeping position and asthma exacerbation interact.

\section{Quick Look}

\section{Current Knowledge}

There are few reports on the association between sleeprelated characteristics and asthma exacerbation.

Table 5 Univariate and Multivariate Analyses: Factors Associated with Exacerbation of Asthma in One Year

\begin{tabular}{|c|c|c|c|c|}
\hline & \multicolumn{2}{|c|}{ Univariate Analysis } & \multicolumn{2}{|c|}{ Multivariate Analysis ${ }^{\dagger}$} \\
\hline & $\begin{array}{l}\text { Odds Ratio } \\
(95 \% \mathrm{Cl})\end{array}$ & $p$ value & $\begin{array}{l}\text { Odds Ratio } \\
(95 \% \mathrm{Cl})\end{array}$ & $p$ value \\
\hline Age, one year increase, year & $\begin{array}{c}1.001 \\
(0.960-1.044)\end{array}$ & 0.951 & & \\
\hline $\begin{array}{l}\text { Severe persistent asthma (versus mild intermittent asthma, mild persistent asthma, and } \\
\text { moderate persistent asthma) }\end{array}$ & $\begin{array}{c}10.67 \\
(2.607-43.64)\end{array}$ & $0.001 *$ & $\begin{array}{c}8.627 \\
(1.263-58.92)\end{array}$ & $0.028^{*}$ \\
\hline ACT score, one point increase, point & $\begin{array}{c}0.720 \\
(0.601-0.862)\end{array}$ & $<0.001 *$ & $\begin{array}{l}0.745 \\
(0.605-0.918)\end{array}$ & $0.006 *$ \\
\hline FeNO, one ppb increase, ppb & $\begin{array}{c}1.005 \\
(0.997-1.013)\end{array}$ & 0.220 & & \\
\hline $\mathrm{pAHI}$, one event increase, events/hour & $\begin{array}{c}0.921 \\
(0.845-1.004)\end{array}$ & 0.061 & & \\
\hline Prevalence of LLD position in sleep monitoring, one point increase, \% & $\begin{array}{c}1.049 \\
(1.012-1.088)\end{array}$ & $0.009 *$ & $\begin{array}{c}1.053 \\
(1.006-1.103)\end{array}$ & $0.028^{*}$ \\
\hline
\end{tabular}

Notes: $*_{p}<0.05$, †multiple logistic regression analysis (forward selection method).

Abbreviations: $\mathrm{Cl}$, confidence interval; ACT, Asthma Control Test; FeNO, fractional exhaled nitric oxide; pAHI, peripheral arterial tone apnea hypopnea index; LLD, left lateral decubitus. 


\section{What This Paper Contributes to Our Knowledge}

The present study identified that the left lateral decubitus sleeping position was associated with future asthma exacerbation.

\section{Statement of Ethics}

All participants provided written informed consent for analysis of their clinical data, and the study was approved by the Ethics Committee of Fukushima Medical University (IRB number 2845). This study was conducted in accordance with the Declaration of Helsinki.

\section{Acknowledgments}

The authors thank Masami Kikuchi of the Department of Pulmonary Medicine, School of Medicine, Fukushima Medical University, for her technical assistance.

\section{Author Contributions}

All authors have a significant contribution to the work reported, whether that was in the conception, study design, execution, acquisition of data, analysis and interpretation, or in all of the following areas: taking part in the drafting, revising or critically reviewing of the manuscript; giving final approval of the version to be published; have agreeing on the journal to which the article has been submitted; and agreeing to be accountable for all aspects of the work. Conception: Suguru Sato, Takaya Kawamata, Takefumi Nikaido, Hiroyuki Minemura, Study design: Suguru Sato, Junpei Saito, Execution: Suguru Sato, Junpei Saito, Atsuro Fukuhara, Manabu Uematsu, Yasuhito Suzuki, Acquisition of data: Suguru Sato, Junpei Saito, Atsuro Fukuhara, Manabu Uematsu, Yasuhito Suzuki, Mami Rikimaru, Tatsuhiko Koizumi, Analysis of data: Suguru Sato, Takashi Umeda, Ryuichi Togawa, Yuki Sato, Takefumi Nikaido, Drafting and revising Manuscript Preparation: Suguru Sato, Junpei Saito, Review of manuscript: Kenya Kanazawa, Yoshinori Tanino, Yoko Shibata.

\section{Funding}

This research did not receive any specific grant from funding agencies in the public, commercial, or not-forprofit sectors.

\section{Disclosure}

Prof. Dr. Yoko Shibata reports personal fees from GSK, Novartis, AstraZeneca, and Boehringer Ingelheim Japan, outside the submitted work. The authors have no other conflicts of interest to disclose.

\section{References}

1. Janson C, De Backer W, Gislason T, et al. Increased prevalence of sleep disturbances and daytime sleepiness in subjects with bronchial asthma: a population study of young adults in three European countries. Eur Respir J. 1996;9(10):2132-2138. doi:10.1183/ 09031936.96.09102132

2. Krouse HJ, Yarandi H, McIntosh J, Cowen C, Selim V. Assessing sleep quality and daytime wakefulness in asthma using wrist actigraphy. J Asthma. 2008;45(5):389-395.

3. van Keimpema AR, Ariaansz M, Nauta JJ, Postmus PE. Subjective sleep quality and mental fitness in asthmatic patients. J Asthma. 1995;32(1):69-74.

4. Vir R, Bhagat R, Shah A. Sleep disturbances in clinically stable young asthmatic adults. Ann Allergy Asthma Immunol. 1997;79 (3):251-255.

5. Teodorescu M, Broytman O, Curran-Everett D, et al. Obstructive sleep apnea risk, asthma burden, and lower airway inflammation in adults in the Severe Asthma Research Program (SARP) II. $J$ Allergy Clin Immunol Pract. 2015;3(4):566-75 e1.

6. Calhoun SL, Vgontzas AN, Fernandez-Mendoza J, et al. Prevalence and risk factors of excessive daytime sleepiness in a community sample of young children: the role of obesity, asthma, anxiety/ depression, and sleep. Sleep. 2011;34(4):503-507.

7. Martin RJ, Cicutto LC, Ballard RD. Factors related to the nocturnal worsening of asthma. Am Rev Respir Dis. 1990;141(1):33-38.

8. Bonnet R, Jorres R, Heitmann U, Magnussen H. Circadian rhythm in airway responsiveness and airway tone in patients with mild asthma. J Appl Physiol (1985). 1991;71(4):1598-1605.

9. Mello-Fujita L, Roizenblat S, Frison CR, et al. Gastroesophageal reflux episodes in asthmatic patients and their temporal relation with sleep architecture. Braz J Med Biol Res. 2008;41 (2):152-158.

10. Kelly EA, Houtman JJ, Jarjour NN. Inflammatory changes associated with circadian variation in pulmonary function in subjects with mild asthma. Clin Exp Allergy. 2004;34(2):227-233. doi:10.1111/j.13652222.2004.01866.x

11. Saito J, Gibeon D, Macedo P, Menzies-Gow A, Bhavsar PK, Chung KF. Domiciliary diurnal variation of exhaled nitric oxide fraction for asthma control. Eur Respir J. 2014;43(2):474-484.

12. Kavanagh J, Jackson DJ, Kent BD. Sleep and asthma. Curr Opin Pulm Med. 2018;24(6):569-573.

13. Julien JY, Martin JG, Ernst P, et al. Prevalence of obstructive sleep apnea-hypopnea in severe versus moderate asthma. J Allergy Clin Immunol. 2009;124(2):371-376.

14. Denlinger LC, Phillips BR, Ramratnam S, et al. Inflammatory and comorbid features of patients with severe asthma and frequent exacerbations. Am J Respir Crit Care Med. 2017;195(3):302-313.

15. Teodorescu M, Barnet JH, Hagen EW, Palta M, Young TB, Peppard PE. Association between asthma and risk of developing obstructive sleep apnea. JAMA. 2015;313(2):156-164.

16. Ciftci TU, Ciftci B, Guven SF, Kokturk O, Turktas H. Effect of nasal continuous positive airway pressure in uncontrolled nocturnal asthmatic patients with obstructive sleep apnea syndrome. Respir Med. 2005;99(5):529-534.

17. Lafond C, Series F, Lemiere C. Impact of CPAP on asthmatic patients with obstructive sleep apnoea. Eur Respir J. 2007;29(2):307-311. 
18. Serrano-Pariente J, Plaza V, Soriano JB, et al. Asthma outcomes improve with continuous positive airway pressure for obstructive sleep apnea. Allergy. 2017;72(5):802-812.

19. Wang Y, Liu K, Hu K, et al. Impact of obstructive sleep apnea on severe asthma exacerbations. Sleep Med. 2016;26:1-5.

20. Standards for the diagnosis and care of patients with chronic obstructive pulmonary disease (COPD) and asthma. This official statement of the American Thoracic Society was adopted by the ATS Board of Directors, November 1986. Am Rev Respir Dis. 1987;136(1):225-244.

21. Ichinose M, Sugiura H, Nagase H, et al. Japanese guidelines for adult asthma 2017. Allergol Int. 2017;66(2):163-189.

22. Sato S, Saito J, Sato Y, et al. Clinical usefulness of fractional exhaled nitric oxide for diagnosing prolonged cough. Respir Med. 2008;102 (10):1452-1459

23. O'Brien LM, Bullough AS, Shelgikar AV, Chames MC, Armitage R, Chervin RD. Validation of Watch-PAT-200 against polysomnography during pregnancy. J Clin Sleep Med. 2012;8(3):287-294.

24. Garg N, Rolle AJ, Lee TA, Prasad B. Home-based diagnosis of obstructive sleep apnea in an urban population. J Clin Sleep Med. 2014;10(8):879-885.

25. Pittman SD, Ayas NT, MacDonald MM, Malhotra A, Fogel RB, White DP. Using a wrist-worn device based on peripheral arterial tonometry to diagnose obstructive sleep apnea: in-laboratory and ambulatory validation. Sleep. 2004;27(5):923-933.

26. Yuceege M, Firat H, Demir A, Ardic S. Reliability of the Watch-PAT 200 in detecting sleep apnea in highway bus drivers. J Clin Sleep Med. 2013;9(4):339-344.

27. Standardization of Spirometry. 1994 Update. American Thoracic Society. Am J Respir Crit Care Med. 1995;152(3):1107-1136.

28. Dweik RA, Boggs PB, Erzurum SC, et al. An official ATS clinical practice guideline: interpretation of exhaled nitric oxide levels (FENO) for clinical applications. Am J Respir Crit Care Med. 2011;184(5):602-615.

29. Nathan RA, Sorkness CA, Kosinski M, et al. Development of the asthma control test: a survey for assessing asthma control. J Allergy Clin Immunol. 2004;113(1):59-65.
30. Menzies-Gow A, Mansur AH, Brightling CE. Clinical utility of fractional exhaled nitric oxide in severe asthma management. Eur Respir J. 2020;55:3.

31. Dunn RM, Busse PJ, Wechsler ME. Asthma in the elderly and late-onset adult asthma. Allergy. 2018;73(2):284-294.

32. Sato S, Saito J, Fukuhara A, et al. The clinical role of fractional exhaled nitric oxide in asthma control. Ann Allergy Asthma Immunol. 2017;119(6):541-547.

33. Backon J, Kullok S. Why asthmatic patients should not sleep in the right lateral decubitus position. $\mathrm{Br} J$ Clin Pract. 1990;44 (11):448-449.

34. Leung RS, Bowman ME, Parker JD, Newton GE, Bradley TD. Avoidance of the left lateral decubitus position during sleep in patients with heart failure: relationship to cardiac size and function. J Am Coll Cardiol. 2003;41(2):227-230.

35. Fujita M, Miyamoto S, Sekiguchi H, Eiho S, Sasayama S. Effects of posture on sympathetic nervous modulation in patients with chronic heart failure. Lancet. 2000;356(9244):1822-1823.

36. Quanjer PH, Tammeling GJ, Cotes JE, Pedersen OF, Peslin R, Yernault JC. Lung volumes and forced ventilatory flows. Eur Respir J. 1993;6(Suppl 16):5-40.

37. Gianinis HH, Antunes BO, Passarelli RC, Souza HC, Gastaldi AC. Effects of dorsal and lateral decubitus on peak expiratory flow in healthy subjects. Braz J Phys Ther. 2013;17(5):435-441.

38. Nascimento JP, Perossi L, Holtz M, Baddini-Martinez JA, De Souza HCD, Gastaldi AC. Peak expiratory flow in obese subjects in different positions. Physiother Theory Pract. 2018;1-8.

39. Fan E, Brodie D, Slutsky AS. Acute respiratory distress syndrome: advances in diagnosis and treatment. JAMA. 2018;319(7):698-710.

40. Richter T, Bellani G, Scott Harris R, et al. Effect of prone position on regional shunt, aeration, and perfusion in experimental acute lung injury. Am J Respir Crit Care Med. 2005;172(4):480-487.

41. Davies SE, Bishopp A, Wharton S, Turner AM, Mansur AH. The association between asthma and obstructive sleep apnea (OSA): a systematic review. J Asthma. 2018;56(2):118-129.

\section{Publish your work in this journal}

The Journal of Asthma and Allergy is an international, peer-reviewed open-access journal publishing original research, reports, editorials and commentaries on the following topics: Asthma; Pulmonary physiology; Asthma related clinical health; Clinical immunology and the immunological basis of disease; Pharmacological interventions and new therapies. The manuscript management system is completely online and includes a very quick and fair peer-review system, which is all easy to use. Visit http://www.dovepress.com/testimonials.php to read real quotes from published authors. 